\title{
Transcriptional and physiological analyses of Fe deficiency response in maize reveal the presence of Strategy I components and $\mathrm{Fe} / \mathrm{P}$ interactions
}

\author{
Laura Zanin $^{1 *}$ (D) Silvia Venuti ${ }^{1}$, Anita Zamboni ${ }^{2}$, Zeno Varanini ${ }^{2}$, Nicola Tomasi ${ }^{1}$ and Roberto Pinton ${ }^{1}$
}

\begin{abstract}
Background: Under limited iron (Fe) availability maize, a Strategy /l plant, improves Fe acquisition through the release of phytosiderophores (PS) into the rhizosphere and the subsequent uptake of Fe-PS complexes into root cells. Occurrence of Strategy-I-like components and interactions with phosphorous (P) nutrition has been hypothesized based on molecular and physiological studies in grasses.

Results: In this report transcriptomic analysis (NimbleGen microarray) of Fe deficiency response revealed that maize roots modulated the expression levels of 724 genes (508 up- and 216 down-regulated, respectively). As expected, roots of Fe-deficient maize plants overexpressed genes involved in the synthesis and release of 2'-deoxymugineic acid (the main PS released by maize roots). A strong modulation of genes involved in regulatory aspects, Fe translocation, root morphological modification, primary metabolic pathways and hormonal metabolism was induced by the nutritional stress. Genes encoding transporters for $\mathrm{Fe}^{2+}$ (ZmNRAMP1) and P (ZmPHT1;7 and ZmPHO1) were also up-regulated under Fe deficiency.

Fe-deficient maize plants accumulated higher amounts of $\mathrm{P}$ than the Fe-sufficient ones, both in roots and shoots. The supply of $1 \mu \mathrm{M}{ }^{59} \mathrm{Fe}$, as soluble (Fe-Citrate and Fe-PS) or sparingly soluble (Ferrihydrite) sources to deficient plants, caused a rapid down-regulation of genes coding for PS and Fe(III)-PS transport, as well as of ZmNRAMP1 and ZmPHT1;7. Levels of ${ }^{32} \mathrm{P}$ absorption essentially followed the rates of ${ }^{59} \mathrm{Fe}$ uptake in Fe-deficient plants during Fe resupply, suggesting that $P$ accumulation might be regulated by Fe uptake in maize plants.
\end{abstract}

Conclusions: The transcriptional response to Fe-deficiency in maize roots confirmed the modulation of known genes involved in the Strategy /I and revealed the presence of Strategy / components usually described in dicots. Moreover, data here presented provide evidence of a close relationship between two essential nutrients for plants, Fe and P, and highlight a key role played by Fe and P transporters to preserve the homeostasis of these two nutrients in maize plants.

Keywords: Zea mays, Iron, Fe-source, Gene expression, Mineral nutrition, NRAMP, Phosphate transporter, Phosphorous uptake, Root acquisition, Strategy II

\footnotetext{
* Correspondence: laura.zanin@uniud.it

${ }^{1}$ Dipartimento di Scienze Agroalimentari, Ambientali e Animali, University of

Udine, via delle Scienze 206, I-33100 Udine, Italy

Full list of author information is available at the end of the article
}

(c) The Author(s). 2017 Open Access This article is distributed under the terms of the Creative Commons Attribution 4.0 International License (http://creativecommons.org/licenses/by/4.0/), which permits unrestricted use, distribution, and reproduction in any medium, provided you give appropriate credit to the original author(s) and the source, provide a link to the Creative Commons license, and indicate if changes were made. The Creative Commons Public Domain Dedication waiver (http://creativecommons.org/publicdomain/zero/1.0/) applies to the data made available in this article, unless otherwise stated. 


\section{Background}

Iron (Fe) deficiency is a yield-limiting factor and a worldwide problem for crop production in many agricultural regions, particularly in aerobic and calcareous soils [1]. Although the total Fe content of soil would be sufficient to meet the needs of plants, most of the Fe in the soil is present in poorly available inorganic forms, especially under aerobic conditions [2]. The level of plant-available Fe in the soil solution is determined by a variety of natural ligands (such as microbial siderophores, humic substances and root exudates) which are able to mobilize Fe from oxides/hydroxides form to Fe(III) chelates [3] and can be used by plants directly or through reduction-based mechanisms. In fact it is well known that plants react to low Fe availability using different adaptive strategies. Strategy $I$ is used by all dicots and non-graminaceous monocots, that respond to Fe-deficiency by releasing in the rhizosphere protons and chelating/reducing agents (as carboxylates and phenolic compounds) to mobilize Fe from sparingly soluble forms. Afterwards, a ferric-chelate reductase at the surface of root cells (FRO) mediates the reduction of ferric ions to ferrous form $[4,5]$. The ferrous ion is, in turn, acquired by roots through a $\mathrm{Fe}^{2+}$ transporter belonging to the ZIP metal transporter family (iron regulated metal transporter, IRT) [6].

Graminaceous species, like maize, improve Fe acquisition by releasing phytosiderophores (PS) into the rhizosphere through the PS-efflux transporter TOM1 [7, 8]. Thereafter, the intact Fe(III)-PS complex is taken up through the specific transporter yellow stripe1 (YS1) [9].

In grasses the presence of Strategy I-like mechanisms have also been hypothesized [10]. In rice, that is considered to use a combined strategy, the presence of IRT-like protein and natural-resistance-associated-macrophage protein (NRAMP, also known as divalent metal transporter) have been reported to play important roles in the absorption and translocation of ferrous Fe [10-14]. Besides the efflux of phytosiderophores, rice plants possess a dedicated efflux transporter for phenolic compounds (phenolics efflux zero-like transporter, PEZ [15], which is an essential component in order to improve Fe solubilisation from apoplastic space. Genes coding for ZIP transporters, putative $\mathrm{H}^{+}$-ATPase and $\mathrm{Fe}^{3+}$-reductase have been identified in maize $[16,17]$, although they have not been clearly related to $\mathrm{Fe}$ acquisition. Furthermore, OsNRAMP homologous transporter have been identified in maize and reported as responsive element to Fe deficiency [8]. In this way, in monocot species like rice, and putatively in other graminaceous species, the low availability of Fe might be counteracted also by the activation of some molecular components, not exclusively relating to Strategy II, involved in the acidification of the rhizosphere and the acquisition of ferrous iron forms. The presence of phenolic compounds and carboxylates in the rhizosphere would help Fe solubilisation, which in turn might be taken up by rice or maize roots via Fe(III)-PS transporter (YS1) or, possibly, as ferrous form by IRT-like/NRAMP transporters.

As it might be expected, a complex response to a specific nutritional stress, including the biosynthesis in plants and the release into the rhizosphere of root exudates, would affect uptake and metabolism of other nutrients. Several studies have shown that a low availability of $\mathrm{Fe}$ triggers molecular responses linked to sulphur (S), zinc (Zn) and phosphorous (P) metabolism [18-20]. While the interactions between Fe and S nutrition has been well established [21], there is still poor knowledge about the relationships between Fe and P nutrition in plants, mainly limited to model Strategy I plant Arabidopsis [22, 23] and especially in grasses. In rice seedlings, evidence has been provided about antagonistic interactions between $\mathrm{Fe}$ and $\mathrm{P}$ nutrition. In fact a $\mathrm{P}$ deficiency condition resulted in a significant increase in Fe content within plants while the presence of P limited Fe accumulation in plant tissues [20]. In plants, this antagonistic interaction might be due to the mechanisms used by plants to mobilize poorly soluble source of Fe and $\mathrm{P}$ from soils, i.e. by releasing organic acids and phenolic compounds [24].

Aim of the present work was to study, at physiological and transcriptional level, the Fe deficiency response in maize plants, an economically important crop and a model species for Strategy II.

Starting from morphological observations, we characterized the maize root transcriptome. Moreover deep investigations were conducted to evaluate the capability of maize plants to use different Fe sources, such as FeCitrate, Fe-PS and the sparingly soluble Ferrihydrite. A relationship between Fe deficiency response and $\mathrm{P}$ acquisition processes was also investigated.

\section{Methods \\ Plant material and growth conditions}

Maize seeds (Zea mays L., inbred line PR33T56, Pioneer Hybrid Italia S.p.A.) were germinated over aerated $0.5 \mathrm{mM} \mathrm{CaSO}_{4}$ solution in a dark growth chamber at $25{ }^{\circ} \mathrm{C}$. Five-day-old seedlings were transferred in a continuously aerated $\mathrm{Fe}$-free nutrient solution (containing, $\mu \mathrm{M}: \mathrm{NH}_{4} \mathrm{NO}_{3}$ 1000; $\mathrm{CaSO}_{4} 500 ; \mathrm{MgSO}_{4} 100 ; \mathrm{KH}_{2} \mathrm{PO}_{4}$ 175; KCl 5; $\mathrm{H}_{3} \mathrm{BO}_{3} 2.5 ; \mathrm{MnSO}_{4} 0.2 ; \mathrm{ZnSO}_{4} 0.2 ; \mathrm{CuSO}_{4}$ $0.05 ; \mathrm{Na}_{2} \mathrm{MoO}_{4} 0.05$; buffered solution to $\mathrm{pH} 6.0$ with $2.5 \mathrm{mM}$ 2-(N-morpholino) ethanesulfonic acid (MES)$\mathrm{KOH})$ and plants were grown for 7 days in a growth chamber under controlled climatic conditions (day/night photoperiod, 16/8 h; radiation, $220 \mu$ Einsteins $\mathrm{m}^{-2} \mathrm{~s}^{-1}$; day/ night temperature, $25 / 20{ }^{\circ} \mathrm{C}$; relative humidity, $70-80 \%$ ). Thereafter, some 12-day old plants were maintained for a 
further week in Fe deficiency (Fe-deficient plants, -Fe), while some of 12-day-old maize plants were transferred to a Fe-sufficient nutrient solution containing $100 \mu \mathrm{M}$ Fe-EDTA (Fe-sufficient plants, +Fe). Nutrient solutions were renewed every three days. During the growth period, light transmittance of leaves was determined on 12-day-old plants, 15-day old plants and 19-day old plants using a portable chlorophyll meter SPAD-502 (Minolta, Osaka, Japan) and presented as SPAD index values.

After 14 days of growing in Fe-free nutrient solution, 19-day-old maize plants showed visual symptoms of Fe deficiency (interveinal yellowing of the young leaves; increase in the diameter of the sub-apical zone and amplified root hair formation). The capability of Fe-deficient and Fe-sufficient plants to acidify the rhizosphere was investigated using the $\mathrm{pH}$ indicator bromocresol purple. Thus, whole root systems of intact plants were placed on a 3-mm-thick gel layer containing $0.9 \%$ agar, $0.01 \%$ bromocresol purple and buffered at pH 5.5 with $1 \mathrm{M} \mathrm{KOH}$.

Elemental analyses were assessed on roots and shoots of 19-day old Fe-deficient and Fe-sufficient plants. Dried samples of roots and leaves were dried, ashed at $550^{\circ}$ and digested with $\mathrm{H}_{2} \mathrm{O}_{2}$. Thereafter, samples were diluted with $3.75 \% \mathrm{HNO}_{3}$ and filtered through a Whatman WCN $0.2 \mu \mathrm{m}$ membrane filter. Iron, calcium $(\mathrm{Ca})$, potassium (K), magnesium (Mg), manganesium (Mn), sodium (Na), P, S and $\mathrm{Zn}$ concentrations ( $\mathrm{mg} \mathrm{Kg}^{-1}$ dry weight) were then determined by ICP-OES (VISTA-MPX, Varian Inc., Palo Alto, USA).

For microarray analyses, roots of Fe-deficient and Fesufficient maize plants (19-d old) were harvested three hours after the beginning of light phase. The collected roots were immediately frozen in liquid nitrogen and stored until further processing at $-80{ }^{\circ} \mathrm{C}$. The collection was repeated in three independent cultivations and the roots from six plants were pooled for each treatment.

\section{Microarray analyses}

RNA extractions were performed using the Invisorb Spin Plant RNA kit (Stratec Molecular) as reported in the manufacturer's instructions. Maize roots $(70 \mathrm{mg})$ were homogenized in liquid nitrogen and the powder was mixed with $900 \mu \mathrm{l}$ of DCT solution and dithiothreitol according to the supplier's instructions. The RNA quality and quantity were determined using a Bioanalyzer Chip RNA 6000 series II (Agilent).

For the microarray analyses, three independent biological replicates were used, for a total of 6 hybridizations. The cDNA synthesis, labeling, hybridization and washing reactions were performed according to the NimbleGen Arrays User's Guide (http://www.nimblegen.com/). Each hybridization was carried out on a NimbleGen microarray (Roche, NimbleGen Inc.), representing 59,756 transcripts predicted from the B73 reference genome (http:// ftp.maizesequence.org/release-5b/filtered-set/). A complete description of the chip is available at the Gene Expression Omnibus (http://www.ncbi.nlm.nih.gov/geo) under the series entry (GPL17540). The microarray was scanned using an Axon GenePix 4400 (Molecular Devices) at $532 \mathrm{~nm}$ (Cy-3 absorption peak) and GenePix Pro7 software (Molecular Devices) according to the manufacturers' instructions. Images were analyzed using NimbleScan v2.5 software (Roche), which produces Pair Files containing the raw signal intensity data for each probe and Calls Files with normalized expression data- (quantile normalization) derived probe summarization through RMA analysis [25]. Analysis of normalized data (Calls Files) was performed using the open source software of the Bioconductor project (http://www.bioconductor.org/) [26] with the statistical R programming language (http://www.r-project.org/) [27]. Differentially expressed probes were identified by linear model analysis [28] using the LIMMA package and applying Bayesian correction, adjusted $P$-value $\leq 0.05, n=3, \quad F C \geq$ |1.5|. All microarray expression data are available at the Gene Expression Omnibus (http://www.ncbi.nlm.nih.gov/ geo/) under the series entry (GSE76829).

\section{Physiological and transcriptional experiments with natural Fe sources: Fe-PS, Fe-Citrate and Ferrihydrite Preparation of Fe-sources}

Soluble Fe-sources (Fe-PS and Fe-Citrate) were prepared according to von Wirén et al. [29] by mixing an aliquot of Fefree (epi-HMA)-containing root exudates collected from Fedeficient barley plants [30] or citrate (10\% excess) with $\mathrm{FeCl}_{3}$ [or ${ }^{59} \mathrm{FeCl}_{3}$ for radiochemical analyses]. $\mathrm{KH}_{2}^{32} \mathrm{PO}_{4}$ solution were prepared to a final concentration $175 \mu \mathrm{M}$.

The poorly soluble Fe-sources (Ferrihydrite and Vivianite) were prepared according to previous works [31, 32]. Amorphous Ferrihydrite [or $\left({ }^{59} \mathrm{Fe}\right)$ Ferrihydrite] was obtained by precipitating $\mathrm{Fe}\left(\mathrm{NO}_{3}\right)_{3}$ [or $\left.{ }^{59} \mathrm{Fe}\left(\mathrm{NO}_{3}\right)_{3}\right]$ at alkaline $\mathrm{pH}$, with the addition of $1 \mathrm{M} \mathrm{KOH}$ [31]. The synthetic $\left({ }^{32} \mathrm{P}\right)$ Vivianite was obtained through the slow neutralization of $50 \mathrm{mM} \mathrm{FeSO}_{4}$ in $35 \mathrm{mM} \mathrm{H}_{3}^{32} \mathrm{PO}_{4}$ with $50 \mathrm{mM} \mathrm{KOH}$ at room temperature. The $\mathrm{pH}$ of the mixture was brought up to 6 , where the precipitation of a blue-grey powder occurred. The powder was washed via centrifugation with distilled water to remove the presence of salt. One milliliter of suspension containing respectively of Ferrihydrite [or $\left({ }^{59} \mathrm{Fe}\right)$ Ferrihydrite] $(2 \mu \mathrm{mol}$ $\mathrm{Fe})$ or $\left({ }^{32} \mathrm{P}\right)$ Vivianite $(2 \mu \mathrm{mol} \mathrm{P})$ were transferred into a dialysis tube (ZelluTrans/Roth 6.0, $\varnothing 16 \mathrm{~mm}$, exclusion limit of 8-10 kDa, ROTH, Karlsruhe, Germany).

\section{Iron uptake from soluble and poorly soluble sources by maize plants}

To evaluate the capability of Fe-deficient plants to use natural Fe sources, physiological and transcriptional 
experiments were performed on 19-day old intact maize plants.

The day before of the experiment, roots of (18-d old) Fe-deficient plants were washed 3 times with deionized water. Then, two intact plants were transferred to beakers containing $230 \mathrm{ml}$ of a freshly prepared Fe-free nutrient solution. The next day, Fe-PS, Fe-Citrate or Ferrihydrite were added to give a final Fe concentration of $1 \mu \mathrm{M}$ and the treatment solutions were buffered at $\mathrm{pH} 6.0$ with $10 \mathrm{mM}$ MES-KOH. The photochemical reduction phenomena of $\mathrm{Fe}$ in the nutrient solution [33], was limited covering the beakers with black plastic foils during the entire experiment. During the time span of $24 \mathrm{~h}$ (after 1, 4, and 24 h) root samples were harvested, frozen in liquid nitrogen and used for the gene expression analyses. The same experimental setup was used for radiochemical analyses where ${ }^{59} \mathrm{Fe}$-sources were supplied to Fe-deficient and Fe-sufficient plants at a final $\mathrm{Fe}$ concentration of $1 \mu \mathrm{M}{ }^{59} \mathrm{Fe}-\mathrm{PS},{ }^{59} \mathrm{Fe}-\mathrm{Citrate}$ or $\left({ }^{59} \mathrm{Fe}\right)$ Ferrihydrite and at a specific activity of $144 \mathrm{kBq} \mu \mathrm{mol}^{-1} \mathrm{Fe}$ (Perkin Elmer, Monza, Italy). At each time-point ( 1 and $24 \mathrm{~h}$ of treatment) plants were transferred into cold deionized water for $10 \mathrm{~min}$ in order to stop Fe uptake and remove the excess of ${ }^{59} \mathrm{Fe}$ at the root surface. Root apoplastic ${ }^{59} \mathrm{Fe}$ pools were removed as described by Bienfait et al. [34], raising roots in a solution (1.2 $\mathrm{g} \mathrm{l}^{-1}$ sodium dithionite, $1.5 \mathrm{mM} \mathrm{2,2}$ '-bipyridyl and $\left.1 \mathrm{mM} \mathrm{Ca}\left(\mathrm{NO}_{3}\right)_{2}\right)$ under $\mathrm{N}_{2}$ bubbling gas. After roots and leaves were harvested and collected separately in vials. Root and shoot tissues were oven dried at $80{ }^{\circ} \mathrm{C}$, weighed, ashed at $550{ }^{\circ} \mathrm{C}$, and suspended in $1 \mathrm{M} \mathrm{HCl}$ for ${ }^{59} \mathrm{Fe}$ determination by liquid scintillation counting. The ${ }^{59} \mathrm{Fe}$ accumulation was measured as nanomoles of ${ }^{59} \mathrm{Fe}$ and is presented as nmol ${ }^{59} \mathrm{Fe} \mathrm{g}^{-1}$ root dry weight.

\section{Real-time $R T-P C R$ experiments}

To validate the microarray results and to analyze in time-course the expression profile of some genes during $24 \mathrm{~h}$ of Fe-source treatments, real-time RT-PCR analyses were performed. Total RNA was treated with 1 $\mathrm{U} \mu \mathrm{g}^{-1}$ RNA of DNase I (Sigma Aldrich) and cDNA was synthesized from $1 \mu \mathrm{g}$ of RNA following the application protocol of the manufacturers $\left[42{ }^{\circ} \mathrm{C}\right.$ for $1 \mathrm{~h}$ with $1 \mathrm{pmol}$ of oligod(T) ${ }_{23} \mathrm{VN}$ (Sigma Aldrich); $15 \mathrm{U}$ of Prime RNase Inhibitor (Eppendorf); $10 \mathrm{U}$ of $\mathrm{M}$-MulV RNase $\mathrm{H}-$ (Finnzymes)]. After RNA digestion with $1 \mathrm{U}$ of RNase A (USB) for $1 \mathrm{~h}$ at $37{ }^{\circ} \mathrm{C}$, gene expression analyses were performed by adding $0.16 \mu \mathrm{l}$ of the cDNA to the realtime RT-PCR complete mix, FluoCycleTM sybr green (20 $\mu$ l final volume; Euroclone, Pero, Italy), in a C1000 Thermal Cycler-Bio-Rad CFX96 real-time PCR detection system (Bio-Rad). The analyses of real-time RT-PCR result were performed using Bio-Rad CFX Manager v.2 software (Bio-Rad).
Real-time RT-PCRs analyses were performed to evaluate the expression level of most interesting identified by microarray and the modulation of these genes was monitored during the time span of Fe-treatments. The primers were designed using Primer3 software [35, 36] and they were synthesized by Sigma Aldrich (gene model ID, forward and reverse primer sequences 5'- -3'): ZmYS1 (GRMZM2G156599, AGGAGACAAGAACGCAAGGA and ACTGAACAAAGCCGCAAACT), ZmTOM1 (GR MZM2G063306, AGGAGTTCTTCTTCGTCGCA and GCACCAAGAAAACCAGCGTA), ZmOPT7 (GRMZM2 G421491, TCGTCTGGAAGGAGGAGATG and CGGTT GCTGGTTAGTGGTG), ZmNRAMP1 (GRMZM2G1781 90, GGAGAATTATGGCGTGAGGA and ACCACCAAA CCGATCAGAAG), ZmFerritin (GRMZM2G325575, GA TGCTGCTTGAGGAAGAGG and CCGACCCAGAGT TGTCAGTT), ZmPHT1;7 (GRMZM2G112377, TCCTG ATGATGACGGTGTTC and GAAGTTGGCGAAGAAG AAGG).

The analyses of real-time RT-PCR results were performed using Bio-Rad CFX Manager v.2 software (Bio-Rad) and R (version 2.9.0; http://www.r-project.org/) with the qPCR package (version 1.1-8; http://www.dr-spiess.de/qpcR.html). Efficiencies of amplification were calculated following the authors' indications [37]. Real-time RT-PCR results were validated using two housekeeping genes, ZmGAPDH (GRMZM2G046804, CCTGCTTCTCATGGATGGTT and TGGTAGCAGGAAGGGAAGCA) and ZmTUA (GRMZM2G152466, AGGTCATCTCATCCCTGACG and TGAAGTGGATCCTCGGGTAG). Data were normalized with respect to the transcript level of the housekeeping genes using the $2^{-\Delta \Delta C T}$ method, where $\Delta \Delta C_{T}=\left(C_{T, T a r g e t}-\right.$ $\left.\mathrm{C}_{\mathrm{T}, \mathrm{HK}}\right)_{\text {Time } \mathrm{x}}-\left(\mathrm{C}_{\mathrm{T}, \text { Target }}-\mathrm{C}_{\mathrm{T}, \mathrm{HK}}\right)_{\text {Time o }}[38]$.

\section{Phosphorous $\left({ }^{32} P\right)$ uptake from soluble and poorly soluble sources by maize plants}

To investigate the effect of natural Fe-sources on the acquisition of P in plants, (19-d old) Fe-deficient and Fesufficient maize plants were treated with three unlabeled-natural Fe sources (Fe-Citrate, Fe-PS and Ferrihydrite), as reported above. Moreover, nutrient solution contained also $\left({ }^{32} \mathrm{P}\right)$-radiolabeled sources, as the soluble source $\mathrm{KH}_{2}{ }^{32} \mathrm{PO}_{4}$ or the poorly soluble source $\left({ }^{32} \mathrm{P}\right)$ Vivianite.

Before starting the assay, the roots were washed 2 times for $5 \mathrm{~min}$ in $0.5 \mathrm{mM} \mathrm{CaSO}$, in order to remove the apoplastic component. Afterwards the plants were transferred into the uptake solution, buffered to $\mathrm{pH} 6.0$ with $10 \mathrm{mM}$ MES-KOH and containing phosphorus supplied as $\mathrm{KH}_{2}{ }^{32} \mathrm{PO}_{4}$ or $\left({ }^{32} \mathrm{P}\right)$ Vivianite labeled with ${ }^{32} \mathrm{P}$ in an amount equal to $2.47 \mathrm{kBq} \mu \mathrm{mol}^{-1}$. After $24 \mathrm{~h}$, root and leaves of maize plants were sampled and the P accumulation in the tissues was determined. Root samples were transferred for $5 \mathrm{~min}$ in a cold washing solution. In 
this way, the apoplastic radioactive component was removed and the uptake of ${ }^{32} \mathrm{P}$ was blocked. Roots and leaves were harvested and collected separately and oven dried at $80{ }^{\circ} \mathrm{C}$, weighed, ashed at $550{ }^{\circ} \mathrm{C}$, and suspended in $1 \mathrm{M} \mathrm{HCl}$. The determination of ${ }^{32} \mathrm{P}$ concentration was performed by liquid scintillation counting. The ${ }^{32} \mathrm{P}$ accumulation, measured as nanomoles of ${ }^{32} \mathrm{P}$ and is presented as $\mathrm{nmol}{ }^{32} \mathrm{P} \mathrm{g}^{-1}$ root dry weight.

\section{Statistical analyses}

Physiological and transcriptomic analyses were performed on three independent biological replicates obtained from independent experiments $(n=3)$; for each sample a pool of six plants was used. Statistical significance was determined by one-way analysis of variance (ANOVA) using Student-Newman-Keuls test $(P<0.05$, $n=3)$. Statistical analyses were performed using SigmaPlot Version 12.0 software. Statistical analysis of microarray data was performed using linear model analysis [28] of the LIMMA package after Bayesian correction with Bioconductor software, adjusted $P$-value $\leq 0.05, n=$
3, $\mathrm{FC} \geq|1.5|$ (for details see the 'Microarray analyses' section).

\section{Results \\ Morphological comparison between Fe-deficient and Fe-sufficient maize plants}

At the end of the growing period, Fe-deficient plants showed typical symptoms of Fe-starvation (Fig. 1, Additional file 1: Figure S1). Indeed Fe-deficient plants showed visible interveinal yellowing of the young leaves (Fig. 1a,b) with a reduction in the chlorophyll content (SPAD index value, Additional file 1: Figure S1). The nutritional stress induced changes also in the root architecture: -Fe plants showed shorter roots and an overall reduction in the morphometric parameters of the root apparatus (Additional file 2: Table S1). Furthermore, $-\mathrm{Fe}$ roots showed an increased in the diameter of the subapical root zone (Fig. 1c,d) with high density of root hairs and a concomitant increased acidification of the external solution (Additional file 1: Figure S2). The multi-element analysis showed lower amounts of Fe in Fe-deficient plants as compare to sufficient ones, and,
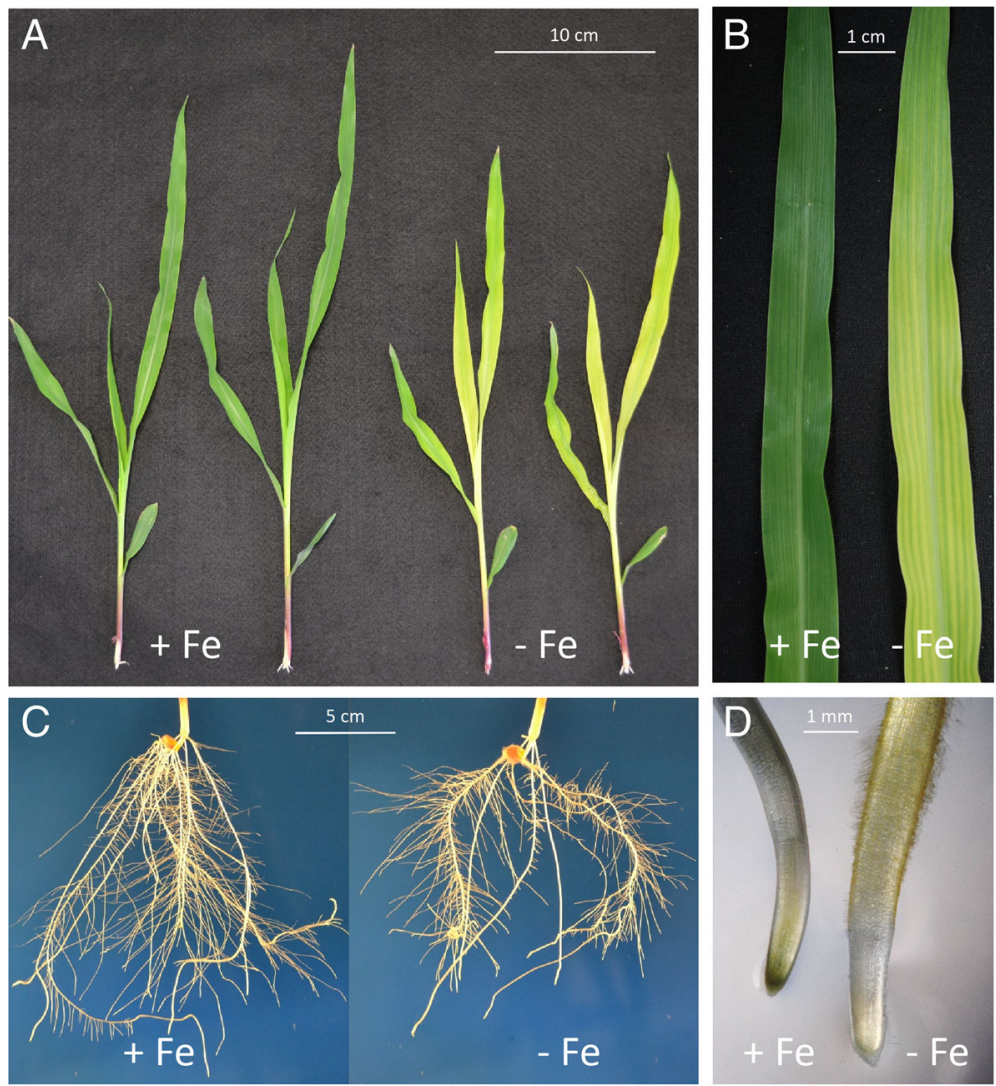

Fig. 1 Shoot and root apparatus of maize plants grown under different Fe-supply conditions. a, shoots of Fe-sufficient plants (left) and shoots of Fe-deficient plants (right); b, leaf details of Fe-sufficient (left) and Fe-deficient (right) plants. c, roots of Fe-sufficient plants (left) and roots of Fe-deficient plants (right); d, details of root tips of Fe-sufficient (left) and Fe-deficient (right) plants after soaking roots with pH indicator (bromocresol purple), as indicated in Methods 
only in roots, low amounts of S. On the other hand, deficient plants accumulated higher amounts of $\mathrm{Mg}$, $\mathrm{Zn}, \mathrm{P}$ and, only in leaves, $\mathrm{Ca}$ and $\mathrm{Na}$ (Fig. 2).

\section{Root transcriptomic response to Fe deficiency}

In order to investigate the Fe-deficient response in maize, microarray analyses were performed on samples of Fe-deficient and Fe-sufficient roots. Analyses were performed using the maize chip 12_135K Arrays from
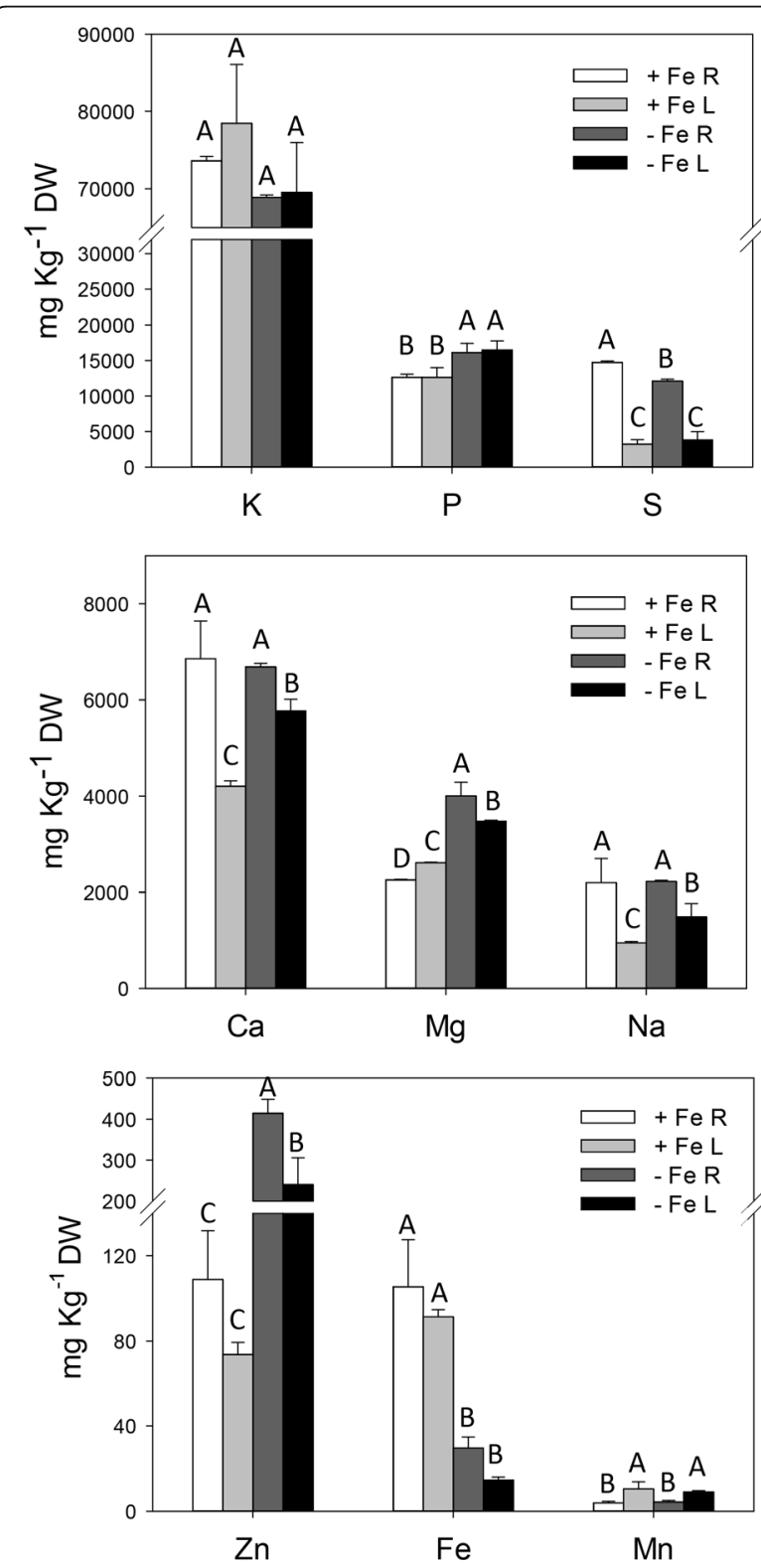

Fig. 2 Macro- and micronutrient concentration $\left[\mathrm{mg} \mathrm{Kg}^{-1}\right.$ dry weight $(D W)]$ in roots $(R)$ and leaves $(L)$ of 19-day-old maize plants grown under Fe sufficiency $(+F e)$ or Fe deficiency $(-F e)$. Data are means + SD of three independent experiments (capital letters refer to statistically significant differences among samples for a single nutrient, ANOVA Holm-Sidak, $P<0.05, n=3$ )
Roche NimbleGen (http://www.nimblegen.com) which allowed the monitoring of 59,756 transcripts. Transcriptional profiles were identified and statistically analyzed by Linear Models for MicroArray (LIMMA) [28], adjusted $P$-value $\leq 0.05, n=3$, fold change $(\mathrm{FC}) \geq|1.5|$. Results indicate that Fe starvation induced changes in the root transcriptome involving 724 transcripts, 508 of which were up-regulated while 216 were down-regulated (Additional file 3: Table S2).

The differentially expressed transcripts were annotated based on the description file provided by Phytozome (Zea mays 284_6a JGI download) and clustered under functional categories according to the biological process of Gene Ontology (GO, http://www.geneontology.org). Referring to the total number of modulated transcripts, the most abundant categories were "metabolic process" (36\% of modulated transcripts), "biological regulation" (11\%), "localization" (10\%) and "cellular process" (6\%), while 33\% of modulated transcripts showed unknown function. The main GO categories included more up-regulated than down-regulated transcripts (Additional file 1: Figure S3).

Global functional analysis based on 'MapMan bins' indicated that Fe deficiency modulated transcripts involved in glycolysis, mitochondrial electron transport/ATP synthesis, hormone metabolism, amino acid metabolism, abiotic stress, secondary metabolism, signaling and membrane transport functions (Fig. 3, Additional file 1: Figure S4).

Among transcripts involved in glycolysis, fermentation and TCA cycle, Fe starvation up-regulated those coding for a glyceraldehyde-3-phosphate dehydrogenase (GADPH), phosphofructokinase (PFK), fructose-bisphosphate aldolase (FBP aldolase) and phosphoenolpyruvate carboxylase (PEPC), pyruvate decarboxylase (PDC), aldehyde dehydrogenase $(\mathrm{ADH})$, lactate/malate dehydrogenase (LDH), citrate synthase (CS), isocitrate dehydrogenase (IDH), NADP-malic enzyme (NADP-ME, Fig. 3, Additional file 3: Table S2).

In agreement with morphological observation at the root level, several transcripts involved in the cell wall formation and lipid synthesis were modulated by $\mathrm{Fe}$ availability (Fig. 3).

In Fe-deficient roots also some pathways for the synthesis of amino acids were induced, especially those for the synthesis of methionine and its derivatives (as phytosyderophores), which play a crucial role in the Strategy II. To provide a clearer representation, the modulated transcripts were mapped on a custom pathway [39] for phytosiderophore synthesis and iron transport in Strategy II plants (Fig. 4). Iron starvation induced the expression of many transcripts involved in the pathway for the synthesis and release in the soil of deoxymugineic acid (DMA, Fig. 4).

Several transcripts encoding transporters were modulated in response to Fe status. In particular our data identified some transcripts putatively involved in the 


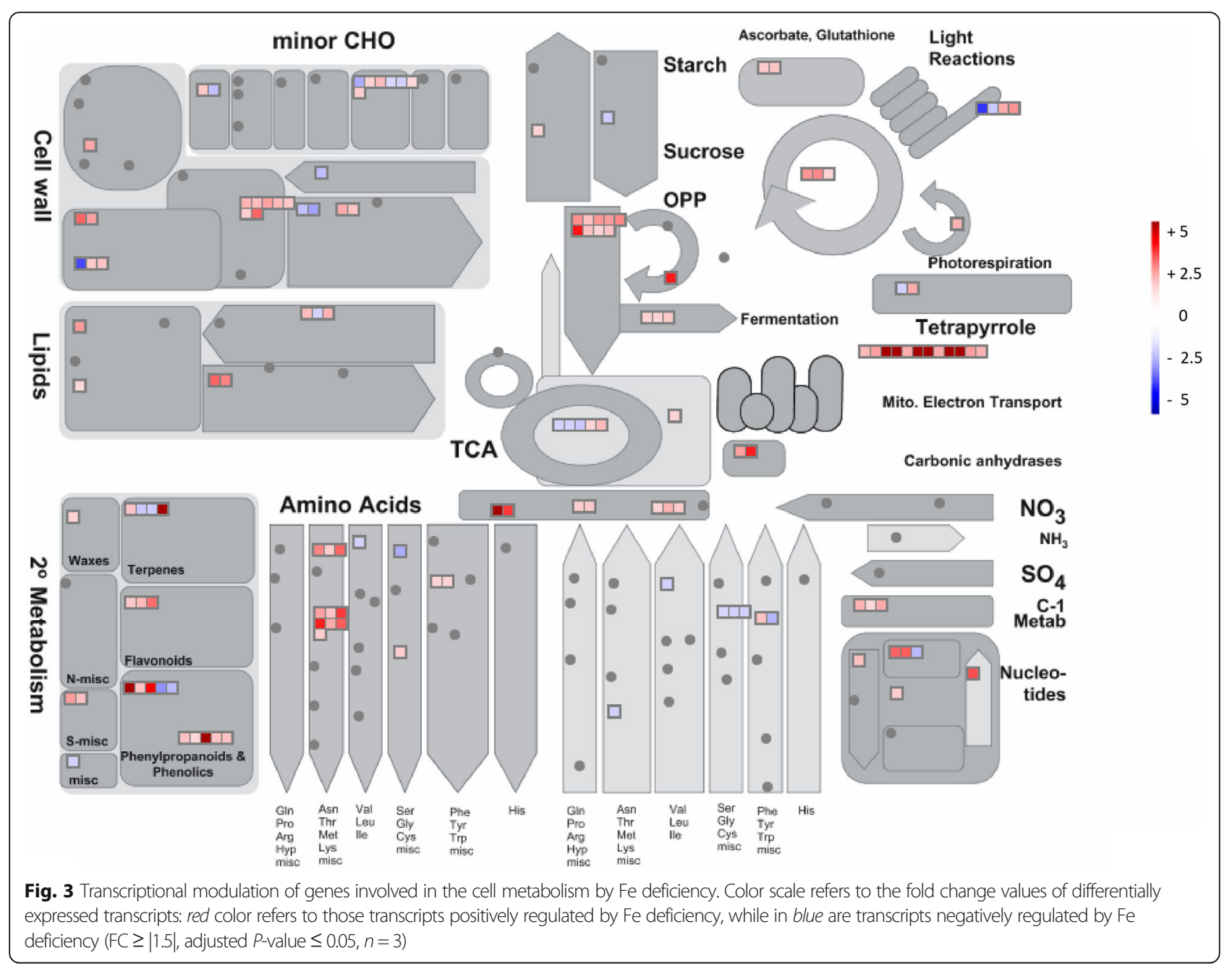

acquisition/translocation of iron (encoding TOM1, VIT1, NRAMP1, OPT7 and YS-like transporters), sulphate/molybdate (MOT1), zinc (ZIFL1, ZIFL2, ZIP4) and even phosphate (PHO1, PHT1;7, Table 1). The modulation of five differentially expressed transcripts in response to Fe deficiency was confirmed through realtime RT-PCR experiments (Fig. 5).

\section{Expression pattern of transcripts encoding transporters in response to Fe supply}

The response of maize plants to Fe deficiency was further evaluated analyzing the capability of Fe-deficient plants to use three different natural Fe-sources (Fe-PS, Fe-Citrate or Ferrihydrite) provided at a concentration $(1 \mu \mathrm{M} \mathrm{Fe})$ conceivably present in soils affected by low $\mathrm{Fe}$ availability.

By real-time RT-PCR, the expression of some transcripts relating to $\mathrm{Fe}$ acquisition were analyzed in Fedeficient roots exposed for up to $24 \mathrm{~h}$ to the different treatments (Fig. 5).
The genes coding for the PS efflux transporter and for $\mathrm{Fe}(\mathrm{III})-\mathrm{PS}$ influx transporter, ZmTOM1 and ZmYS1 respectively, were positively modulated by Fe deficiency. On the other hand, when Fe-sources were supplied to Fe-deficient plants, the expression levels of these transcripts decreased considerably reaching, after $24 \mathrm{~h}$, mRNA amounts comparable to those of Fe-sufficient plants (Fig. 5a,b). A similar behavior was also observed for $Z m O P T 7$ and ZmNRAMP1, two genes putatively involved in the response to Fe deficiency. The expression of these two genes was already modulated after $4 \mathrm{~h}$ of treatment with the Fe-sources (Fig. 5c,d).

Moreover differences in the expression levels could be appreciated comparing the treatments. After $24 \mathrm{~h}$ of $\mathrm{Fe}$ supply, maize roots down-regulated most transcripts reaching expression levels comparable to those recorded under Fe sufficiency, this effect being particularly evident when Fe-PS was supplied to the nutrient solution (Fig. 5a,b,c,d,f). Concerning ZmOPT7, Fe-deficient maize roots were more responsible when soluble $\mathrm{Fe}$ sources (Fe-PS and Fe-Citrate) were supplied to nutrient 


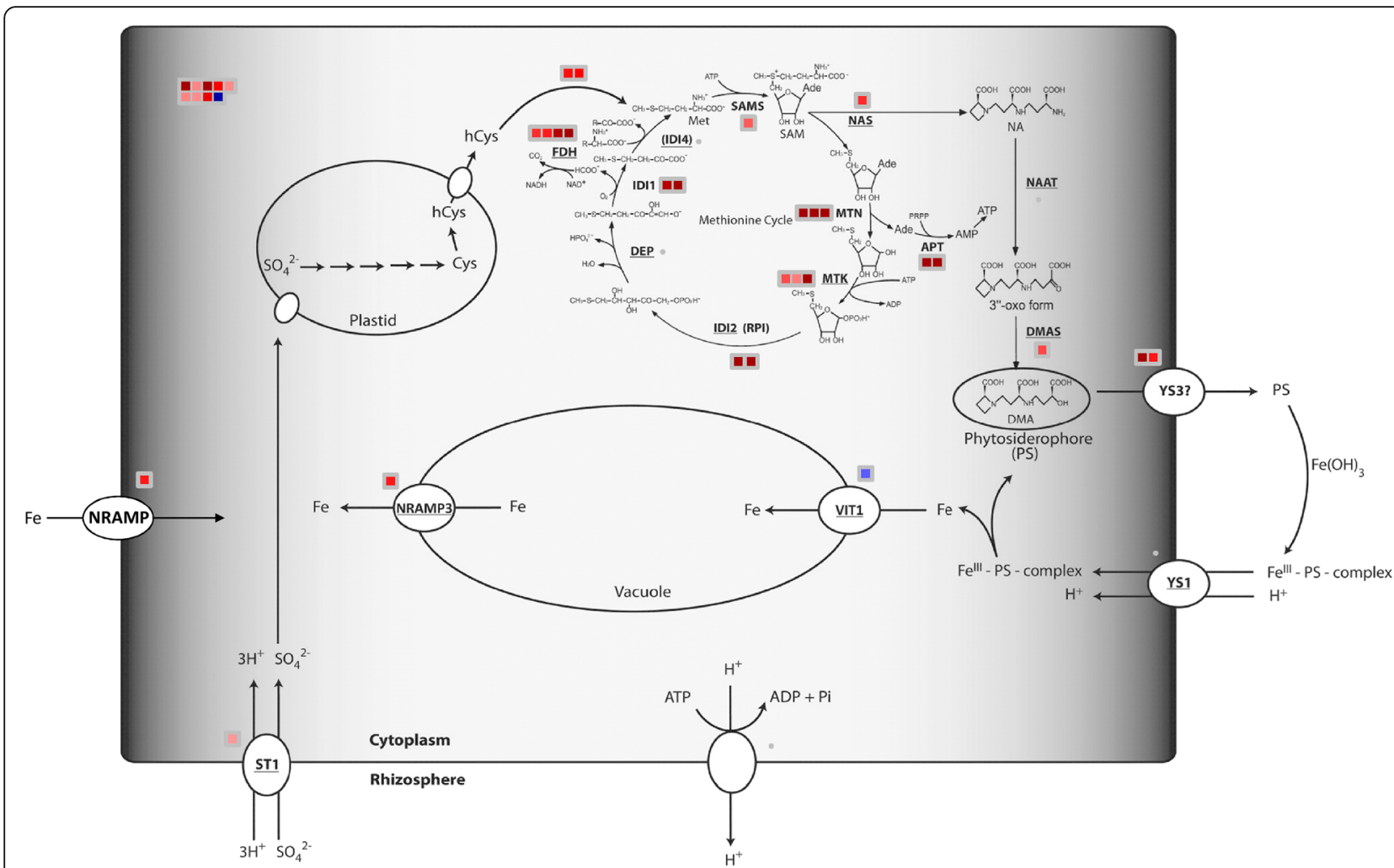

Fig. 4 Transcriptional changes in roots of genes involved in the Methionine cycle/DMA synthesis and Fe acquisition by Fe deficiency. Abbreviations: YS1 = yellow stripe 1; YS3 = yellow stripe 3 (ZmTOM1 gene, GRMZM2G063306); ST1 = Sulfate transporter 1; SO${ }_{4}^{2-}=$ sulfate; Cys = cysteine; hCys = homo-cysteine; $\mathrm{FDH}$ = formate dehydrogenase; DEP = methylthioribulose-1-phosphate dehydratase-enolase-phosphatase; IDI1 = 2-keto-methylthiobutyric-acid forming enzyme; IDI4 = putative aminotransferase catalyzing the synthesis of methionine from 2-keto-methylthiobutyric acid; SAMS = S-adenosyl-methionine synthase; MTN = methylthioadenosine/S-adenosyl homocysteine nucleosidase; MTK = methylthioribose kinase; IDI2 = eukaryotic initiation factor 2B-like methylthio ribose-1-phosphate isomerase; NAS = nicotinamine synthase; NAAT = nicotianamine amino-transferase; DMAS = 2'-deoxymugineicacid synthase; APT = Adenosin phosphoribosyltransferase; VIT1 = vacuolar iron transporter 1; NRAMP = natural resistance associated macrophage protein; Regulation = GRMZM2 G057413 (homology to OsIRO2), GRMZM2G350312 (homology to OsIRO3), GRMZM2G107672 (homology to AtbHLH29), GRMZM2G133675 (homology to AtPYE). Color scale refers to the fold change values of differentially expressed transcripts: red color refers to those transcripts positively regulated by Fe deficiency, while in blue are transcripts negatively regulated Fe deficiency. Adapted from Urbany et al. [39] and Benke et al. [64]

solution. After $24 \mathrm{~h}$ of treatment, deficient plants treated with Fe-PS or Fe-Citrate showed transcript levels comparable to those recorded in Fe-sufficient plants, while higher values were recorded for $Z m O P T 7$ and ZmNRAMP1 when the poorly soluble source Ferrihydrite was supplied (Fig. 5c).

As observed by microarray analyses, Fe deficiency induced also the expression of some transcripts involved in phosphate transport. In particular the expression of $Z m P H T 1 ; 7$, a transcript coding for a phosphate transporter was analyzed when maize plants were treated with the three Fe-sources. Confirming transcriptomic data, the Fe-starved roots accumulated higher amounts of ZmPHT1;7 transcript than Fe-sufficient roots. Supply of Fe-PS or Ferrihydrite rapidly decreased the expression of ZmPHT1;7, while with $\mathrm{Fe}$-Citrate this effect was evident only after $4 \mathrm{~h}$ of treatment (Fig. 5f).
Finally, we evaluated the expression of a gene (ZmFerritin) encoding a ferritin protein, that was highly expressed under Fe sufficiency. The addition of $1 \mu \mathrm{M}$ of soluble $\mathrm{Fe}$ (as Fe-Citrate or Fe-PS) to the Fe-free nutrient solution induced a gradual increase in the gene expression. On the other hand, a low expression of the gene was recorded in roots of $\mathrm{Fe}$-deficient and Ferrihydrite-treated plants (Fig. 5e).

\section{Iron $\left({ }^{59} \mathrm{Fe}\right)$ uptake from different Fe sources}

In order to highlight the ability of maize plants to use the natural Fe-sources, Fe uptake experiments were performed supplying ${ }^{59} \mathrm{Fe}-\mathrm{PS},{ }^{59} \mathrm{Fe}$-Citrate or $\left({ }^{59} \mathrm{Fe}\right)$ Ferrihydrite for $24 \mathrm{~h}$.

The accumulation of ${ }^{59} \mathrm{Fe}$ by the whole plants is reported in Table 2. After $1 \mathrm{~h}$, Fe-deficient plants treated with ${ }^{59} \mathrm{Fe}$-PS accumulated higher levels of ${ }^{59} \mathrm{Fe}$ than the Fe-sufficient ones. A lower ${ }^{59} \mathrm{Fe}$ amount was 
Table 1 List of modulated transcripts involved in the Fe acquisition processes and reported in the Results and Discussion sections by the comparison of transcriptomic profiles of Fe-deficient roots with profile of Fe-sufficient ones, $-\mathrm{Fe}$ vs + Fe comparison (Fold Change $(\mathrm{FC}) \geq|1.5|$, adjusted $P$-value $\leq 0.05, n=3)$

\begin{tabular}{|c|c|c|c|c|c|}
\hline$\#^{\mathrm{a}}$ & Transcript ID & $F C^{c}$ & Description $^{\mathrm{d}}$ & Protein symbol $^{e}$ & Rice gene $I^{f}$ \\
\hline \multicolumn{6}{|c|}{ Strategy /I genes } \\
\hline 1 & GRMZM2G050108_T01 & 2.21 & nicotianamine synthase 4 & NAS & LOC_Os07g48980.1 \\
\hline 2 & GRMZM2G060952_T01 & 2.05 & NAD(P)-linked oxidoreductase superfamily protein & DMAS & LOC_Os03g13390.2 \\
\hline 3 & GRMZM2G063306_T01 & 3.83 & zinc induced facilitator-like 1 & TOM1 & LOC_Os11g04020.1 \\
\hline 4 & GRMZM2G063306_T02 & 2.31 & zinc induced facilitator-like 2 & TOM1 & LOC_Os11g04020.1 \\
\hline \multicolumn{6}{|c|}{ Methionine cycle and DMA synthesis } \\
\hline 5 & GRMZM2G049811_T01 & 2.20 & formate dehydrogenase & $\mathrm{FDH}$ & LOC_Os06g29180.1 \\
\hline 6 & GRMZM2G054123_T01 & 1.94 & S-adenosylmethionine synthetase family protein & SAMS3 & LOC_Os01g22010.1 \\
\hline 7 & GRMZM2G113873_T01 & 1.77 & cystathionine gamma-synthase, putative, expressed & CYS1 & LOC_Os03g25940.4 \\
\hline 8 & GRMZM2G131907_T01 & 3.24 & adenine phosphoribosyl transferase 1 & APT1 & LOC_Os12g39860.1 \\
\hline 9 & GRMZM2G131907_T02 & 3.12 & adenine phosphoribosyl transferase 1 & APT1 & LOC_Os12g39860.1 \\
\hline 10 & GRMZM2G152470_T01 & 2.35 & homocysteine methyltransferase 2 & HMT2 & LOC_Os12g41390.1 \\
\hline 11 & GRMZM2G152470_T03 & 2.43 & homocysteine methyltransferase 2 & HMT2 & LOC_Os12g41390.1 \\
\hline 12 & GRMZM2G165998_T01 & 2.90 & RmlC-like cupins superfamily protein & ARD2 & LOC_Os03g06620.1 \\
\hline 13 & GRMZM2G165998_T02 & 3.03 & acireductone dioxygenase 1 & ARD1 & LOC_Os03g06620.1 \\
\hline 14 & GRMZM2G171111_T01 & 3.20 & Phosphorylase superfamily protein & MTN2 & LOC_Os06g02220.1 \\
\hline 15 & GRMZM2G171111_T02 & 3.53 & methylthioadenosine nucleosidase 1 & MTN1 & LOC_Os06g02220.1 \\
\hline 16 & GRMZM2G171111_T04 & 3.77 & methylthioadenosine nucleosidase 1 & MTN1 & LOC_Os06g02220.1 \\
\hline 17 & GRMZM2G362021_T01 & 2.29 & formate dehydrogenase & $\mathrm{FDH}$ & LOC_Os06g29180.1 \\
\hline 18 & GRMZM2G464137_T01 & 2.03 & S-methyl-5-thioribose kinase & MTK & LOC_Os04g57400.1 \\
\hline 19 & GRMZM2G464137_T02 & 1.73 & S-methyl-5-thioribose kinase & MTK & LOC_Os04g57400.1 \\
\hline 20 & GRMZM2G464137_T03 & 3.11 & S-methyl-5-thioribose kinase & MTK & LOC_Os04g57400.1 \\
\hline 21 & GRMZM5G891282_T01 & 3.82 & ribose-5-phosphate isomerase 2 & $\mathrm{RPI} 2$ & LOC_Os04g24140.1 \\
\hline 22 & GRMZM2G057506_T02 & 1.67 & & & LOC_Os01g72360.1 \\
\hline 23 & GRMZM2G131907_T02 & 3.12 & adenine phosphoribosyl transferase 1 & APT1 & LOC_Os12g39860.1 \\
\hline 24 & GRMZM2G131907_T01 & 3.24 & adenine phosphoribosyl transferase 1 & APT1 & LOC_Os12g39860.1 \\
\hline 25 & GRMZM2G418005_T02 & 1.57 & formate dehydrogenase & $\mathrm{FDH}$ & LOC_Os06g29180.1 \\
\hline \multicolumn{6}{|c|}{ Transcription factors } \\
\hline 26 & GRMZM2G057413_T01 & 3.20 & basic helix-loop-helix DNA-binding domain containing protein, expressed & IRO2 & LOC_Os01g72370.1 \\
\hline 27 & GRMZM2G057413_T02 & 10.07 & basic helix-loop-helix DNA-binding domain containing protein, expressed & IRO2 & LOC_Os01g72370.1 \\
\hline 28 & AC193786.3_FGT005 & 2.44 & basic helix-loop-helix DNA-binding domain containing protein, expressed & IRO4 & LOC_Os01g72370.1 \\
\hline 29 & GRMZM2G350312_T01 & 1.63 & basic helix-loop-helix DNA-binding domain containing protein, expressed & IRO3 & LOC_Os03g26210.1 \\
\hline 30 & GRMZM2G350312_T03 & 1.68 & basic helix-loop-helix DNA-binding domain containing protein, expressed & IRO4 & LOC_Os03g26210.1 \\
\hline 31 & GRMZM2G350312_T04 & 1.62 & basic helix-loop-helix DNA-binding domain containing protein, expressed & IRO5 & LOC_Os03g26210.1 \\
\hline 32 & GRMZM2G107672_T01 & 2.58 & FER-like regulator of iron uptake & FER-like & LOC_Os04g31290.1 \\
\hline 33 & GRMZM5G898290_T01 & 1.62 & NAC domain containing protein 80 & NAC & LOC_Os02g36880.4 \\
\hline 34 & GRMZM5G898290_T02 & 2.32 & NAC domain containing protein 80 & NAC & LOC_Os02g36880.4 \\
\hline \multicolumn{6}{|c|}{ Other genes } \\
\hline 35 & GRMZM2G029135_T01 & 1.62 & 1-aminocyclopropane-1-carboxylate synthase & ACCS & LOC_Os01g08270.1 \\
\hline 36 & AC148152.3_FGT005 & 2.25 & 1-aminocyclopropane-1-carboxylate oxidase & AACO & LOC_Os03g48430.1 \\
\hline 37 & GRMZM2G041418_T01 & 50.74 & alternative $\mathrm{NAD}(\mathrm{P}) \mathrm{H}$ dehydrogenase & $\mathrm{ADH} 2$ & LOC_Os07g37730.1 \\
\hline
\end{tabular}


Table 1 List of modulated transcripts involved in the Fe acquisition processes and reported in the Results and Discussion sections by the comparison of transcriptomic profiles of Fe-deficient roots with profile of Fe-sufficient ones, $-F e$ vs + Fe comparison (Fold Change (FC) $\geq|1.5|$, adjusted $P$-value $\leq 0.05, n=3$ ) (Continued)

\begin{tabular}{|c|c|c|c|c|c|}
\hline \multicolumn{6}{|c|}{ Transporters } \\
\hline 38 & GRMZM2G178190_T01 & 2.31 & NRAMP metal ion transporter & NRAMP1 & LOC_Os03g11010.1 \\
\hline 39 & GRMZM2G112377_T01 & 2.30 & phosphate transporter $1 ; 7$ & $\mathrm{PHT} 1 ; 7$ & LOC_Os08g45000.1 \\
\hline 40 & GRMZM5G891944_T01 & 2.19 & phosphate transporter 1 , putative, expressed & $\mathrm{PHO} 1 ; \mathrm{H} 1$ & LOC_Os01g02000.1 \\
\hline 41 & GRMZM2G064657_T01 & 2.63 & phosphate transporter 1 , putative, expressed & $\mathrm{PHO} 1 ; \mathrm{H1}$ & LOC_Os06g29790.1 \\
\hline 42 & GRMZM2G421491_T01 & 11.76 & oligopeptide transporter, putative, expressed & OPT7 & LOC_Os03g54000.1 \\
\hline
\end{tabular}

accumulated when plants were supplied with the other two ${ }^{59} \mathrm{Fe}$-sources $\left({ }^{59} \mathrm{Fe}\right.$-Citrate or $\left({ }^{59} \mathrm{Fe}\right)$ Ferrihydrite) and no significant difference was recorded comparing the two growth conditions (+Fe and $-\mathrm{Fe})$.

Most of the accumulated ${ }^{59} \mathrm{Fe}$ was retained in the roots, with the exception of Fe-sufficient plants treated with ${ }^{59} \mathrm{Fe}$-Citrate (Table 2, Additional file 1: Figure S5).

At the end of the experiment $(24 \mathrm{~h})$, the amount of ${ }^{59} \mathrm{Fe}$ in whole plants was dependent on the Fe-source supplied to nutrient solution and on the nutritional status. In Fesufficient plants ${ }^{59} \mathrm{Fe}$ accumulation increased following the sequence: $\quad\left({ }^{59} \mathrm{Fe}\right)$ Ferrihydrite $<{ }^{59} \mathrm{Fe}$-Citrate $<{ }^{59} \mathrm{Fe}-\mathrm{PS}$. Fedeficient plants ${ }^{59} \mathrm{Fe}$ accumulated almost the same amount of ${ }^{59} \mathrm{Fe}$ from the soluble sources; a much lower amount of ${ }^{59} \mathrm{Fe}$ was accumulated in plants treated with Ferrihydrite $\left(\left({ }^{59} \mathrm{Fe}\right)\right.$ Ferrihydrite $<{ }^{59} \mathrm{Fe}$-Citrate $={ }^{59} \mathrm{Fe}-\mathrm{PS}$, Table 2$)$.

In Fe-sufficient plants translocation accounted for $c a$. $70 \%$ of the absorbed ${ }^{59} \mathrm{Fe}$ when ${ }^{59} \mathrm{Fe}$-Citrate and ${ }^{59} \mathrm{Fe}-\mathrm{PS}$ were supplied, while only ca. $15 \%$ in presence of $\left({ }^{59} \mathrm{Fe}\right)$ Ferrihydrite.

Iron-deficient plants showed a translocation rate of about $55 \%$ and $31 \%$ when supplied with ${ }^{59} \mathrm{Fe}-\mathrm{PS}$ or ${ }^{59} \mathrm{Fe}-$ Citrate, respectively, while only about $4 \%$ when the poorly soluble source $\left(\left({ }^{59} \mathrm{Fe}\right)\right.$ Ferrihydrite $)$ was provided (Table 2).

\section{Phosphorous $\left({ }^{32} \mathrm{P}\right)$ uptake as affected by Fe nutrition}

To investigate a possible influence of Fe-nutritional status of plants on phosphate uptake, the ${ }^{32} \mathrm{P}$ accumulation was measured after a 24-h exposure to the three different Fesources (Ferrihydrite, Fe-Citrate or Fe-PS) in presence of two different ${ }^{32} \mathrm{P}$ sources: $\mathrm{KH}_{2}^{32} \mathrm{PO}_{4}$, as a soluble form, and $\left({ }^{32} \mathrm{P}\right)$ Vivianite, as a poorly soluble source (Table 3$)$. Fesufficient plants supplied with $\mathrm{KH}_{2}^{32} \mathrm{PO}_{4}$ showed a higher accumulation of ${ }^{32} \mathrm{P}$ and a higher translocation rates as compared to the Fe-deficient ones. In the sufficient plants ${ }^{32} \mathrm{P}$ accumulation was unaffected by the Fe treatment.
Fe-deficient plants showed similar levels of ${ }^{32} \mathrm{P}$ accumulation from $\mathrm{KH}_{2}^{32} \mathrm{PO}_{4}$ when supplied with Fe-Citrate or Fe-PS, but almost double as compared to Ferrihydrite supply.

Uptake from $\left({ }^{32} \mathrm{P}\right)$ Vivianite was extremely low and almost unaffected by the nutritional status and Fe-source supplied (Table 3, Additional file 1: Figure S6).

\section{Discussion}

Characterization of Fe deficiency responses in maize roots Morphological and transcriptome response to Fe deficiency was analyzed in 19-day-old maize plants. Besides typical symptoms of Fe deficiency in leaves (interveinal chlorosis), also roots showed morphological changes, such as a thicker subapical root zone with proliferation of root hairs; these changes, together with an intense acidification of the root external medium, have been widely reported for dicots [40, 41]. However, proliferation of lateral roots has also been reported in maize [42].

Microarray analysis of more than 60,000 maize transcripts revealed that Fe deficiency modulated in roots about 700 transcripts, 508 of which were up-regulated while 216 were down-regulated. This result is in agreement with previous observations showing that the plant response to Fe deficiency is based on the modulation of a narrow set of transcripts [39, 41, 43, 44].

Considering the crucial role of $\mathrm{Fe}$ as cofactor of a wide range of enzymes, many genes encoding for cytochromes, catalase, peroxidase isozymes, ferredoxin, and isozymes of superoxide dismutase were found downregulated by Fe deficiency in maize roots.

On the other hand, grasses counteract Fe starvation by inducing the expression of those genes involved in the Strategy II adaptive mechanism. Microarray results showed the up-regulation of several transcripts involved in methionine cycle (SAMS, MTN, MTK, IDI2, FDH) and in the synthesis and release of MAs (NAS, DMAS, TOM1). The synchronous modulation by Fe deficiency 

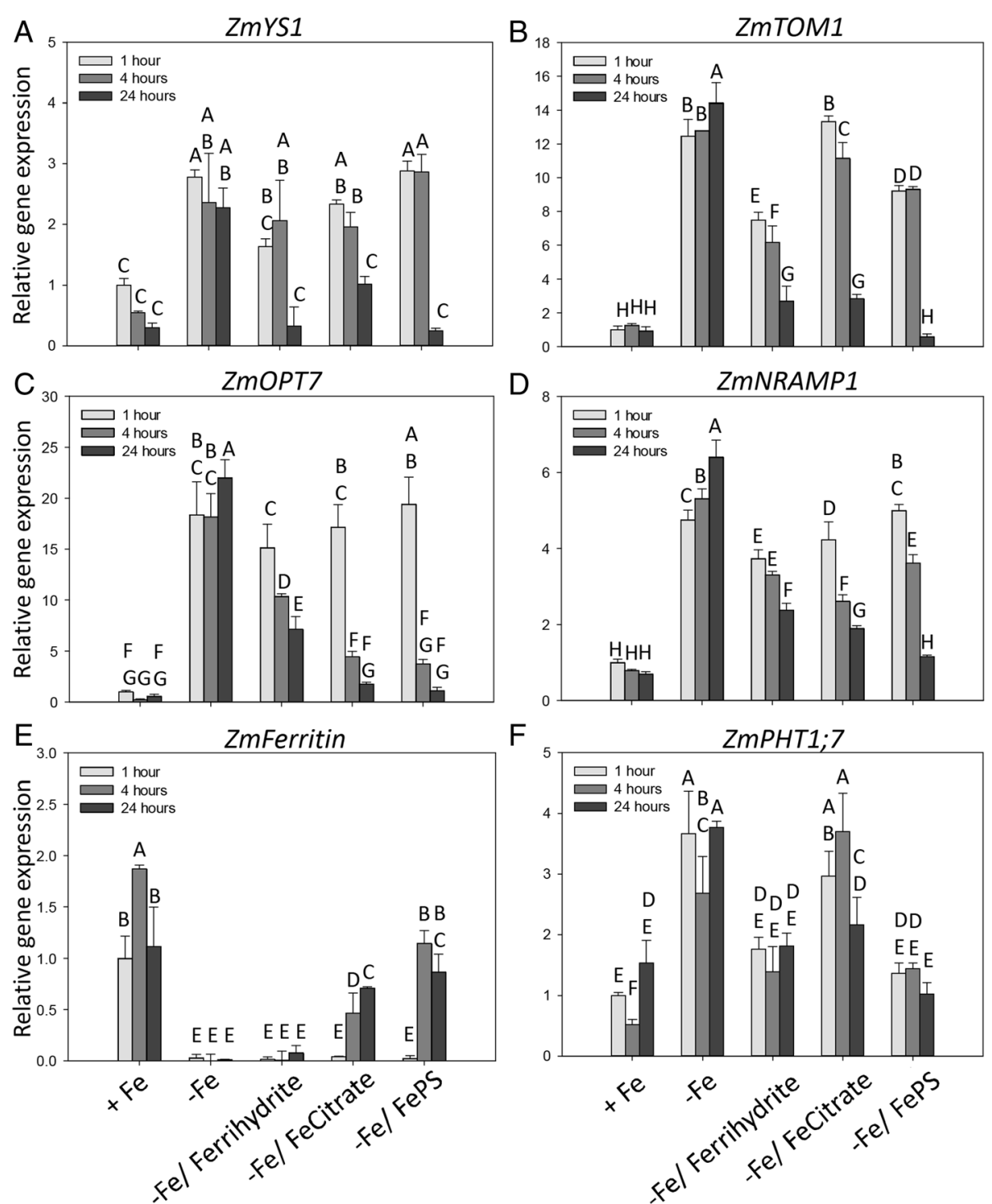

Fig. 5 Real-time RT-PCR analyses of gene transcript levels in maize roots. Nineteen-day-old maize plants were grown under Fe sufficiency (+Fe) or Fe deficiency (-Fe); these latter were then supplied with three different Fe-sources: Ferrihydrite, Fe-Citrate or Fe-PS (-Fe/Ferrihydrite, -Fe/Fe-Citrate or -Fe/Fe-PS, respectively). Root samples were harvested after 1, 4 and $24 \mathrm{~h}$ from the beginning of the experiment. Analyzed genes: a, ZmYS1 (GRMZM2G156599); b, ZmTOM1 (GRMZM2G063306); c, ZmOPT7 (GRMZM2G421491); d, ZmNRAMP1 (GRMZM2G178190); e, ZmFerritin (GRMZM2G325575); f, ZmPHT1;7 (GRMZM2G112377). Real-time RT-PCR results were validated using two housekeeping genes, ZmGAPDH and ZmTUA, in this figure results normalized on $Z m G A P D H$ are shown. Gene mRNA levels were normalized with respect to the mean transcript level of the housekeeping gene $Z m G A P D H$; relative changes in gene transcript levels were calculated on the basis of the mean transcript level of $Z m G A P D H$ in Fe-sufficient roots at $1 \mathrm{~h}$ (relative gene expression $=1$ ). Data are means of three independent biological replicates + SD (ANOVA Holm-Sidak, $P<0.05, n=3$ )

of this pathway was reported in previous works $[8,39]$. This response might be correlated with the induction of different IRO transcription factors observed in maize roots (Table 1). The modulation of genes coding for several IRO transcription factors and two formatedehydrogenase (FDH) isoforms was previously reported in maize roots under low Fe availability [39]; these results strengthen the hypothesis of a strong correlation between Fe deficiency response and the modulation of the enzymes involved in the methionine cycle.
As precursors, SAM metabolites also sustain the synthesis of the phytohormone ethylene, which is induced in Strategy $I$ plants and rice by $\mathrm{Fe}$ deficiency [45]. Among differentially modulated transcript, data indicated the up-regulation of transcripts coding for ACC synthetase and ACC oxidase, which are directly involved in the synthesis of ethylene. In balance with auxin and cytokinin levels, ethylene might be associated with morphological changes in roots controlling root hair proliferation under Fe deficiency [46]. However the role of 
Table 2 Iron- $\left({ }^{59} \mathrm{Fe}\right)$ accumulated in maize plants and percentage distribution in leaves and roots

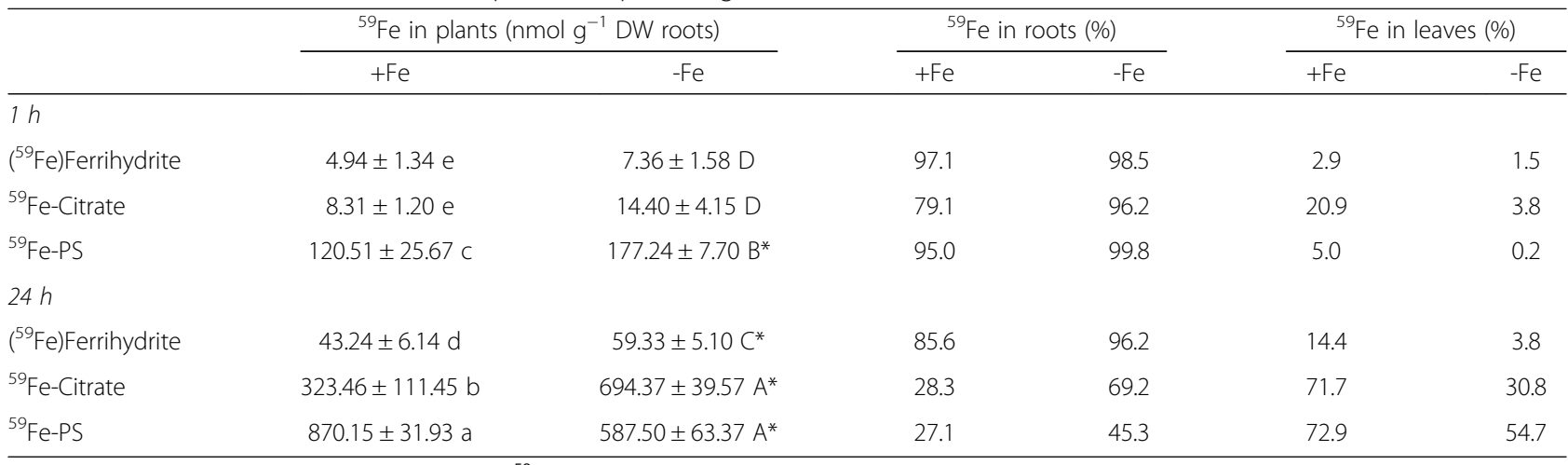

The plant ability to accumulate Fe was evaluated by ${ }^{59} \mathrm{Fe}$ uptake experiments on Fe-sufficient (+Fe) and Fe-deficient (-Fe) plants treated for 1 and $24 \mathrm{~h}$ with three labelled ${ }^{59} \mathrm{Fe}$-sources: $\left({ }^{59} \mathrm{Fe}\right)$ Ferrihydrite, ${ }^{59} \mathrm{Fe}$-Citrate or ${ }^{59} \mathrm{Fe}-\mathrm{PS}$. Data are means $\pm \mathrm{SD}$ of three independent experiments. Small letters, refer to statistically significant differences among Fe-sufficient plants; capital letters, refer to statistically significant differences among Fe-deficient plants, asterisks, refer to statistically significant differences between the two growth condition (-Fe vs + Fe). ANOVA Holm-Sidak, $P<0.05, n=3$ ). DW, dry weight

ethylene in Strategy II plants is still unclear [42, 45]. No evidence of higher ethylene production has been provided in several Strategy II plants [45], with the exception of rice, which is characterized by a combined strategy [47]. A clear up-regulation of genes involved in ethylene synthesis has been reported in rice [9], while in maize genes related to the methionine cycle and involved in MAs synthesis have been shown to be induced under Fe-deficiency [42]. Further research on the involvement of ethylene, and its relationships with other hormones, in the morphological and physiological changes occurring in Strategy II plants is needed.

Microarray data identified other pathways positively modulated by Fe deficiency in maize roots, such as glycolysis, TCA cycle and mitochondrial chain reactions. Similar transcriptional changes in primary metabolism have been described in many species under Fe deficiency $[20,41,48]$. In particular transcripts coding for an alternative dehydrogenase and an alternative oxidase (AOX1) were strongly induced by Fe starvation in maize roots (present work). As reported by Vigani and Zocchi $[49,50]$, the induction of these enzymes might be a valid strategy to synthetize ATP bypassing the impairment of the ubiquinone (UQ) reduction process occurring under Fe deficiency.

\section{Use of different Fe sources by Fe-deficient maize plants} Starting from transcriptional evidence on Fe-deficient roots, we focused our study on the ability of maize plants to use three different natural Fe-sources: FeCitrate, Fe-PS or Ferrihydrite, added to the external root solution mimicking condition of low Fe availability [30]. Up to now, the capability of plants to use different Fesources occurring in the rhizosphere has been studied mostly in dicots [51].

Table 3 Phosphorous- $\left({ }^{32} \mathrm{P}\right)$ accumulated in maize plants and percentage distribution between leaves and roots

\begin{tabular}{|c|c|c|c|c|c|c|}
\hline & \multicolumn{2}{|c|}{${ }^{32} \mathrm{P}$ in plants ( $\mu \mathrm{mol} \mathrm{g}{ }^{-1} \mathrm{DW}$ roots) } & \multicolumn{2}{|c|}{${ }^{32} \mathrm{P}$ in roots (\%) } & \multicolumn{2}{|c|}{${ }^{32} \mathrm{P}$ in leaves (\%) } \\
\hline & $+\mathrm{Fe}$ & $-\mathrm{Fe}$ & $+\mathrm{Fe}$ & $-\mathrm{Fe}$ & $+\mathrm{Fe}$ & $-\mathrm{Fe}$ \\
\hline \multicolumn{7}{|l|}{$\mathrm{KH}_{2}^{32} \mathrm{PO}_{4}$} \\
\hline Ferrihydrite & $90.93 \pm 5.46 \mathrm{a}$ & $37.74 \pm 5.66 B^{*}$ & 49.2 & 69.5 & 50.8 & 30.5 \\
\hline Fe-Citrate & $104.00 \pm 16.36 a$ & $63.51 \pm 3.43 A^{*}$ & 37.6 & 62.6 & 62.4 & 37.4 \\
\hline Fe-PS & $97.36 \pm 8.66 \mathrm{a}$ & $56.17 \pm 2.09 A^{*}$ & 44.7 & 68.1 & 55.3 & 31.9 \\
\hline \multicolumn{7}{|l|}{${ }^{32}$ P)Vivianite } \\
\hline Ferrihydrite & $0.11 \pm 0.03 b$ & $0.13 \pm 0.01 C$ & 76.0 & 88.7 & 24.0 & 11.3 \\
\hline Fe-Citrate & $0.11 \pm 0.01 \mathrm{~b}$ & $0.13 \pm 0.01 C$ & 76.9 & 88.3 & 23.1 & 11.7 \\
\hline Fe-PS & $0.11 \pm 0.01 b$ & $0.19 \pm 0.02 C^{*}$ & 76.3 & 91.4 & 23.7 & 8.6 \\
\hline
\end{tabular}

The plant ability to accumulate $P$ was evaluated by ${ }^{32} \mathrm{P}$ uptake experiments on Fe-sufficient ( $\left.+\mathrm{Fe}\right)$ and Fe-deficient $(-\mathrm{Fe})$ plants. Up to $24 \mathrm{~h},-\mathrm{Fe}$ and $+\mathrm{Fe}$ plants were treated with three unlabelled Fe-sources (Ferrihydrite, Fe-Citrate or Fe-PS) provided in conjunction with two different labelled ${ }^{32} \mathrm{P}^{2}$-sources: $\mathrm{KH}_{2}^{32} \mathrm{PO}_{4}$ or ${ }^{32}$ P)Vivianite. Data are means \pm SD of three independent experiments. Small letters, refer to statistically significant differences among Fe-sufficient plants; capital letters, refer to statistically significant differences among Fe-deficient plants, asterisks, refer to statistically significant differences between the two growth condition (-Fe vs + Fe). ANOVA Holm-Sidak, $P<0.05, n=3$ ). DW, dry weight 
By real-time RT-PCR the expression of two key genes of Strategy II Fe uptake system was monitored up to 24 h of supply: the PS efflux transporter, ZmTOM1, and the Fe(III)-PS influx transporter, ZmYS1. Both genes were strongly up-regulated in response to Fe deficiency, corroborating microarray data and previous results by other authors [8]. When added to the external solution, Fe was taken up by plants, at levels depending on the solubility of the source. The two transporter genes were strongly down-regulated after $24 \mathrm{~h}$ of treatment, independently from the amount of $\mathrm{Fe}$ accumulated within the plant; this behaviour was due neither to a circadian rhythm (see expression in -Fe plants, Fig. 5) nor to an over accumulation in the root tissue, but rather involved the overall distribution of $\mathrm{Fe}$ within the plants (see uptake and translocation of ${ }^{59} \mathrm{Fe}$, Table 2).

In a recent study Nozoye et al. [8] suggested the involvement of ZmNRAMP1 (GRMZM2G178190) in the acquisition of external ferrous ions, as already reported for the rice homologous OsNRAMP1 and OsNRAMP5 [12-14]. Consistent with this assumption, we found the induction of ZmNRAMP1 in Fe-deficient maize roots; gene expression was down-regulated by the treatment with the three Fe-sources with a pattern reflecting the amount of ${ }^{59} \mathrm{Fe}$ taken up by deficient plants.

Recently, a member of OPT transporter family, AtOPT3 in Arabidopsis [52, 53] and its homologous OsOPT7 in rice [54], has been identified as a responsive element to Fe deficiency. In particular AtOPT3 is a phloem-specific Fe transporter which seems to be essential for the systemic Fe signaling and Fe redistribution within the plant [53]. Transcriptional data of the present work revealed that also in maize roots the homologous gene $\mathrm{ZmOPT7}$ was induced by Fe deficiency and was strongly down-regulated by the supply of soluble Fe-sources already after $4 \mathrm{~h}$ of treatment. These data show that $Z m O P T 7$, which is expressed in roots as $O s O P T 7$, is highly responsive to Fe availability and possibly involved in Fe homeostasis in maize plants.

After $1 \mathrm{~h}$ of treatment Fe-deficient plants acquired more efficiently ${ }^{59} \mathrm{Fe}$ from Fe-PS than from the other Fesources. This behaviour fits with the mechanism of $\mathrm{Fe}$ acquisition in Strategy II plants where the Fe-PS complex is the substrate for the YS1 transporter [55]. On the other hand, when Ferrihydrite or Fe-Citrate are provided, $\mathrm{Fe}$ needs to be chelated prior to uptake $[55,56]$. Nevertheless, after $24 \mathrm{~h}$ of ${ }^{59} \mathrm{Fe}-\mathrm{PS}$ treatment, there was a clear saturation of the amount of Fe accumulated by the root apparatus. This phenomenon could be related to the maintenance of $\mathrm{Fe}$ homeostasis, preventing a toxicity effect during Fe-supply to deficient plants [57].

Ferritin gene is involved in Fe storage and in the detoxification of Fe excess [58]. This gene could be considered as an indicator of the iron nutritional status [59], indeed ZmFerritin was negatively regulated in Fe- deficient maize roots. Data also provide further evidence that Fe-PS is used efficiently by Fe-deficient plants since already after $4 \mathrm{~h}$ of Fe-PS supply, the expression levels of ZmFerritin were comparable to those recorded in Fesufficient plants.

\section{Interaction between Fe and $\mathrm{P}$ nutrition}

Previous studies reported an antagonistic interaction between $\mathrm{Fe}$ and $\mathrm{P}$ nutrition in rice plants [20]. This behaviour was confirmed in the present work since Fedeficient maize plants accumulated higher amounts of $\mathrm{P}$ as compared to sufficient ones (Fig. 2). This results fits with the up-regulation of the phosphate transporter ZmPHT1;7 observed in maize roots and its rapid downregulation upon Fe-supply. The rice homologous of this latter gene $(O s P H T 1 ; 6)$ plays a general role in the acquisition of inorganic $\mathrm{P}$ mediating its high affinity uptake from the rhizosphere and translocation within the plants [60].

It has been shown that low Fe concentration in plant tissues increased the energy demand as well the capacity of oxidative phosphorylation [48]. Moreover P is also an important element for the regulation of a wide range of proteins through post-translational modifications. Recent studies suggest that Fe deficiency induces some changes in the phosphoproteome profile of Arabidopsis roots and this modulation might be linked to a regulative mechanism for Fe homeostasis in plants [61].

Trying to relate Fe uptake with $\mathrm{P}$ uptake, ${ }^{32} \mathrm{P}$ accumulation was measured in maize roots during supply of different Fe-sources to Fe-deficient plants. Using a soluble Psource $\left(\mathrm{KH}_{2}^{32} \mathrm{PO}_{4}\right),{ }^{32} \mathrm{P}$ uptake was lower in Fe-deficient plants than in sufficient ones, particularly when Ferrihydrite was used (Table 3). Furthermore it appeared that levels of ${ }^{32} \mathrm{P}$ absorption essentially followed the rates of ${ }^{59} \mathrm{Fe}$ uptake in Fe-deficient plants, as it was higher when soluble Fe-sources were supplied. These results suggest that $\mathrm{P}$ accumulation might be regulated by Fe uptake in maize plants. In Fe-deficient plants, the low Fe internal concentration might de-repress $\mathrm{P}$ uptake leading to an overexpression of the phosphate transporters and a subsequent overaccumulation of $\mathrm{P}$ within the tissues. When Fe is supplied a balanced $\mathrm{P}$ uptake would occur, possibly avoiding insolubilization of absorbed Fe within the plant tissues. Supporting this idea we also found an overexpression of two transcripts coding for the phosphate transporter PHO1 in Fe-deficient roots. Up-regulation of genes coding for this transporter has been shown to be related to Fe-deficiency response in rice plants [62].

\section{Conclusions}

Results of the present work show that besides the wellcharacterized response to Fe deficiency at physiological and transcriptional levels, maize roots also show morphological modifications of root system and up- 
regulation of transcripts usually found in Strategy I plants [63]. Particularly a role of ethylene and other hormones and ferrous ion transporter would deserve further research.

Furthermore, further evidence for a close relationship between Fe and P homeostasis have been provided that could help shedding light on the reciprocal regulation in the uptake and distribution of the two essential elements in maize plants.

\section{Additional files}

\section{Additional file 1: Figure S1. SPAD index values of leaf tissues were} measured on 12, 15 and 19-day-old maize plants grown under Fe-deficient- or Fe-sufficient-condition (-Fe and + Fe plants, respectively). Figure S2. External acidification of maize roots under Fe deficiency ( $B, D)$ and Fe sufficiency ( $A, C$ ). Figure S3. Functional distribution among Gene Ontology (GO) categories of up- and down-regulated transcripts differentially modulated by Fe deficiency (-Fe vs + Fe transcriptomic comparison). Figure S4. Overview of up- (A) and down- (B) modulated transcripts in -Fe vs + Fe comparison using MapMan-bincode classification. Figure S5. Iron- $\left({ }^{59} \mathrm{Fe}\right)$ accumulated in maize leaves (A) and roots (B). Figure S6. Phosphorous- $\left({ }^{32} \mathrm{P}\right)$ accumulated in maize leaves (A) and roots (B). (PDF $6393 \mathrm{~kb}$ )

Additional file 2: Table S1. Morphometric evaluation of maize roots in response to Fe deficiency. (PDF $51 \mathrm{~kb}$ )

Additional file 3: Table S2. Differentially expressed transcripts resulted by the comparison of root transcriptional profiles of Fe-deficient plants with root transcriptional profile of Fe-sufficient ones (-Fe vs + Fe). (XLSX 160 kb)

\section{Abbreviations}

EDTA: Ethylenediaminetetraacetic acid; epi-HMA: Epi-hydroxymugineic acid; MES: 2-(N-morpholino) ethanesulfonic acid

\section{Acknowledgements}

We thank the Functional Genomics Lab of University of Verona for the assistance in microarray experiments.

\section{Funding}

Research was supported by grants from Italian MIUR (FIRB-Programma "Futuro in Ricerca" RBFR127WJ9).

\section{Availability of data and materials}

All microarray expression data and a complete description of the maize chip are available at the Gene Expression Omnibus (http://www.ncbi.nlm.nih.gov/ geo) under the series entry (GSE76829 and GPL17540, respectively).

\section{Authors' contributions}

LZ and AZ performed the transcriptional analyses (microarray and real-time RT-PCR analyses); SV and NT performed physiological analyses (multi-element and radiochemical analyses); LZ SV, NT contributed to data interpretation and manuscript drafting. AZ, ZV and RP participated in the project's design and coordination and critically revised the manuscript. All authors read and approved the final manuscript.

\section{Competing interests}

The authors declare that they have no competing interests.

\section{Consent for publication}

Not applicable.

\section{Ethics approval and consent to participate}

Not applicable.

\section{Author details}

'Dipartimento di Scienze Agroalimentari, Ambientali e Animali, University of Udine, via delle Scienze 206, I-33100 Udine, Italy. ${ }^{2}$ Dipartimento di
Biotecnologie, University of Verona, Ca' Vignal 1- Strada Le Grazie 15, I-37134 Verona, Italy.

Received: 10 August 2016 Accepted: 29 December 2016

Published online: 13 February 2017

\section{References}

1. Mengel K, Kirkby EA, Kosegarten H, Appel T. Principles of plant nutrition. 5th ed. Dordrecht: Kluwer; 2001.

2. Lindsay WL. Role of chelation in micronutrient availability. In: Carson EW, editor. The plant root and its environment. Charlottesville: University Press of Virginia; 1974. p. 507-24.

3. Lindsay WL, Schwab AP. The chemistry of iron in soils and its availability to plants. J Plant Nutr. 1982;5:821-40.

4. Chaney RL, Brown JC, Tiffin LO. Obligatory reduction of ferric chelates in iron uptake by soybeans. Plant Physiol. 1972;50:208-13.

5. Robinson NJ, Procter CM, Connolly EL, Guerinot ML. A ferric-chelate reductase for iron uptake from soil. Nature. 1999:397:694-7.

6. Eide D, Broderius M, Fett J, Guerinot ML. A novel iron-regulated metal transporter from plants identified by functional expression in yeast. PNAS. 1996;93:5624-8

7. Nozoye T, Nagasaka S, Kobayashi T, Takahashi M, Sato Y, Sato Y, et al. Phytosiderophore efflux transporters are crucial for iron acquisition in graminaceous plants. J Biol Chem. 2011;286:5446-54.

8. Nozoye T, Nakanishi H, Nishizawa NK. Characterizing the crucial components of iron homeostasis in the maize mutants ys 1 and ys3. PLoS ONE. 2013;8:e62567

9. Kobayashi T, Nishizawa NK. Iron uptake, translocation, and regulation in higher plants. Annu Rev Plant Biol. 2012;63:131-52.

10. Ishimaru Y, Suzuki M, Tsukamoto T, Suzuki K, Nakazono M, Kobayashi T, et al. Rice plants take up iron as an $\mathrm{Fe}^{3+}$-phytosiderophore and as $\mathrm{Fe}^{2+}$. Plant J. 2006:45:335-46.

11. Bughio N, Yamaguchi H, Nishizawa NK, Nakanishi H, Mori S. Cloning an ironregulated metal transporter from rice. J Exp Bot. 2002;53:1677-82.

12. Takahashi $R$, Ishimaru $Y$, Senoura $T$, Shimo H, Ishikawa S, Arao T, et al. The OsNRAMP1 iron transporter is involved in Cd accumulation in rice. J Exp Bot. 2011:62:4843-50.

13. Ishimaru Y, Bashir K, Nakanishi H, Nishizawa NK. OsNRAMP5, a major player for constitutive iron and manganese uptake in rice. Plant Signal Behav. 2012;7:763-6.

14. Ishimaru Y, Takahashi R, Bashir K, Shimo H, Senoura T, Sugimoto K, et al. Characterizing the role of rice NRAMP5 in manganese, iron and cadmium transport. Sci Rep. 2012;2:286.

15. Bashir K, Ishimaru Y, Shimo H, Kakei Y, Senoura T, Takahashi R, et al. Rice phenolics efflux transporter 2 (PEZ2) plays an important role in solubilizing apoplasmic iron. Soil Sci Plant Nutr. 2011;57:803-12.

16. Li S, Zhou X, Huang Y, Zhu L, Zhang S, Zhao Y, et al. Identification and characterization of the zinc-regulated transporters, iron-regulated transporterlike protein (ZIP) gene family in maize. BMC Plant Biol. 2013;13:114.

17. Li S, Zhou J, Chen J, Chen R. Is there a strategy I iron uptake mechanism in maize? Plant Signal Behav. 2016; doi: 10.1080/15592324.2016.1161877.

18. Ciaffi M, Paolacci AR, Celletti S, Catarcione G, Kopriva S, Astolfi S. Transcriptional and physiological changes in the $S$ assimilation pathway due to single or combined $\mathrm{S}$ and Fe deprivation in durum wheat (Triticum durum L.) seedlings. J Exp Bot. 2013;64:1663-75.

19. Kanai M, Hirai M, Yoshiba M, Tadano T, Higuchi K. Iron deficiency causes zinc excess in Zea mays. Soil Sci Plant Nutr. 2010;55:271-6.

20. Zheng L, Huang F, Narsai R, Wu J, Giraud E, He F, et al. Physiological and transcriptome analysis of iron and phosphorus interaction in rice seedlings. Plant Physiol. 2009;151:262-74.

21. Zuchi S, Watanabe M, Hubberten HM, Bromke M, Osorio S, Fernie AR, et al. The Interplay between Sulfur and Iron Nutrition in Tomato. Plant Physiol. 2015:169:2624-39.

22. Bournier M, Tissot N, Mari S, Boucherez J, Lacombe E, Briat JF, et al. Arabidopsis ferritin 1 (AtFer1) gene regulation by the phosphate starvation response 1 (AtPHR1) transcription factor reveals a direct molecular link between iron and phosphate homeostasis. J Biol Chem. 2013;288:22670-80.

23. Li W, Lan P. Genome wide analysis of overlapping genes regulated by iron deficiency and phosphate starvation reveals new interactions in Arabidopsis roots. BMC Res Notes. 2015;8:555. 
24. Hirsch J, Marin E, Floriani M, Chiarenza S, Richaud P, Nussaume L, et al. Phosphate deficiency promotes modification of iron distribution in Arabidopsis plants. Biochimie. 2006;88:1767-71.

25. Irizarry RA, Bolstad BM, Collin F, Cope LM, Hobbs B, Speed TP. Summaries of Affymetrix GeneChip probe level data. Nucleic Acids Res. 2003;31:e15.

26. Gentleman RC, Carey VJ, Bates DM, Bolstad B, Dettling M, Dudoit S, et al. Bioconductor: open software development for computational biology and bioinformatics. Genome Biol. 2004;5:R80.

27. Ihaka R, Gentleman R. R: A language for data analysis and graphics. J Comput Graph Stat. 1996;5:299-314.

28. Smyth GK. Limma: linear models for microarray data. In: Gentleman R, Carey V, Dudoit S, Irizarry R, Huber W, editors. Bioinformatics and computational biology solutions using R and Bioconductor. New York: Springer; 2005. p. 397-42.

29. Von Wirén N, Mori S, Marschner H, Römheld V. Iron inefficiency in maize mutant ys1 (Zea mays L cv yellow-stripe) is caused by a defect in uptake of iron phytosiderophores. Plant Physiol. 1994;106:71-7.

30. Tomasi N, Nobili M, Gottardi S, Zanin L, Mimmo T, Varanini Z, et al. Physiological and molecular characterization of Fe acquisition by tomato plants from natural Fe complexes. Biol Fertil Soils. 2013;49:187-200.

31. Guzman G, Alcantara E, Barron V, Torrent J. Phytoavailability of phosphate absorbed on ferrihydrite, hematite and goethite. Plant Soil. 1994;159:219-25.

32. Eynard A, del Campillo MC, Barrón V, Torrent J. Use of Vivianite $\left(\mathrm{Fe}_{3}\left(\mathrm{PO}_{4}\right)_{2}\right.$ $8 \mathrm{H}_{2} \mathrm{O}$ ) to prevent iron chlorosis in calcareous soils. Fert Res. 1992;31:61-7.

33. Zancan S, Cesco S, Ghisi R. Effect of UV-B radiation on iron content and distribution in maize plants. Environ Exp Bot. 2006;55:266-72.

34. Bienfait HF, van den Briel W, Mesland-Mul NT. Free space iron pools in roots: generation and mobilization. Plant Physiol. 1985;78:596-600.

35. Koressaar T, Remm M. Enhancements and modifications of primer design program Primer3. Bioinformatics. 2007;23:1289-91.

36. Untergrasser A, Cutcutache I, Koressaar T, Ye J, Faircloth BC, Remm M, et al. Primer3-new capabilities and interfaces. Nucleic Acid Res. 2012;40:e115.

37. Ritz C, Spiess AN. qpcR: an R package for sigmoidal model selection in quantitative real-time polymerase chain reaction analysis. Bioinformatics. 2008;24:1549-51.

38. Livak KJ, Schmittgen TD. Analysis of relative gene expression data using real-time quantitative PCR and the $2^{\Delta \Delta C t}$ method. Methods. 2001;25:402-8.

39. Urbany C, Benke A, Marsian J, Huettel B, Reinhardt R, Stich B. Ups and downs of a transcriptional landscape shape iron deficiency associated chlorosis of the maize inbreds B73 and Mo17. BMC Plant Biol. 2013;13:213.

40. Santi S, Schmidt W. Laser microdissection-assisted analysis of the functional fate of iron deficiency-induced root hairs in cucumber. J Exp Bot. 2008;59:697-704.

41. Zamboni A, Zanin L, Tomasi N, Pezzotti M, Pinton R, Varanini Z, et al. Genome-wide microarray analysis of tomato roots showed defined responses to iron deficiency. BMC Genomics. 2012;13:101.

42. Li H, Wang N, Zhao F, Song $X$, Yin Z, Huang $R$, et al. Changes in the transcriptomic profiles of maize roots in response to iron-deficiency stress. Plant Mol Biol. 2014;85:349-63.

43. Schmidt W, Buckhout TJ. A hitchhiker's guide to the Arabidopsis ferrome. Plant Physiol Biochem. 2011;49:462-70.

44. Li H, Wang L, Yang ZM. Co-expression analysis reveals a group of genes potentially involved in regulation of plant response to iron-deficiency. Gene. 2015;554:16-24.

45. Lucena C, Romera FJ, García MJ, Alcántara E, Pérez-Vicente R. Ethylene participates in the regulation of Fe deficiency responses in Strategy I plants and in rice. Front Plant Sci. 2015;6:1056.

46. Romera FJ, Lucena C, Alcàntara E. Plant hormones influencing iron uptake in plants. In: Barton LL, Abadia J, editors. Iron nutrition in plants and rhizospheric microorganisms. Dordrecht: Springer; 2007. p. 251-78.

47. Wu J, Wang C, Zheng L, Wang L, Chen Y, Whelan J, et al. Ethylene is involved in the regulation of iron homeostasis by regulating the expression of iron-acquisition-related genes in Oryza sativa. J Exp Bot. 2011;62:667-74.

48. Thimm O, Essigmann B, Kloska S, Altmann T, Buckhout TJ. Response of Arabidopsis to iron deficiency stress as revealed by microarray analysis. Plant Physiol. 2001;127:1030-43.

49. Vigani G, Zocchi G. The fate and the role of mitochondria in Fe-deficient roots of strategy I plants. Plant Signal Behav. 2009;4:375-9.

50. Vigani G, Zocchi G. Effect of Fe deficiency on mitochondrial alternative $\mathrm{NAD}(\mathrm{P}) \mathrm{H}$ dehydrogenases in cucumber roots. J Plant Physiol. 2010;167:666-9.

51. Zamboni A, Zanin L, Tomasi N, Avesani L, Pinton R, Varanini Z, et al. Early transcriptomic response to Fe supply in Fe-deficient tomato plants is strongly influenced by the nature of the chelating agent. BMC Genomics. 2016;17:35.
52. Mendoza-Cózatl DG, Xie Q, Akmakjian GZ, Jobe TO, Patel A, Stacey MG, et al. OPT3 is a component of the iron-signaling network between leaves and roots and misregulation of OPT3 leads to an over-accumulation of cadmium in seeds. Mol Plant. 2014;7:1455-69.

53. Zhai Z, Gayomba SR, Jung H, Vimalakumari NK, Piñeros M, Craft E, Rutzke MA, et al. OPT3 Is a Phloem-Specific Iron Transporter That Is Essential for Systemic Iron Signaling and Redistribution of Iron and Cadmium in Arabidopsis. Plant Cell. 2014;26:2249-64.

54. Bashir K, Ishimaru Y, Itai RN, Senoura T, Takahashi M, An G, et al. (2015). Iron deficiency regulated OsOPT7 is essential for iron homeostasis in rice. Plant Mol Biol. 2014;88:165-76.

55. Curie C, Panaviene Z, Loulergue C, Dellaporta SL, Briat JF, Walker EL. Maize yellow stripe1 encodes a membrane protein directly involved in $\mathrm{Fe}(\mathrm{III})$ uptake. Nature. 2001;409:346-9.

56. Cesco S, Nikolic M, Romheld V, Varanini Z, Pinton R. Uptake of 59Fe from soluble $59 \mathrm{Fe}-$ humate complexes by cucumber and barley plants. Plant Soil. 2002;241:121-8.

57. Connolly EL, Fett JP, Guerinot ML. Expression of the IRT1 metal transporter is controlled by metals at the levels of transcript and protein accumulation. Plant Cell. 2002;14:1347-57.

58. Lescure AM, Proudhon D, Pesey H, Ragland M, Theil EC, Briat JF. Ferritin gene transcription is regulated by iron in soybean cell cultures. PNAS. 1991; 88:8222-6.

59. Itai RN, Ogo Y, Kobayashi T, Nakanishi H, Nishizawa NK. Rice genes involved in phytosiderophore biosynthesis are synchronously regulated during the early stages of iron deficiency in roots. Rice. 2013;6:1.

60. Ai P, Sun S, Zhao J, Fan X, Xin W, Guo Q, et al. Two rice phosphate transporters, OsPht1;2 and OsPht1;6, have different functions and kinetic properties in uptake and translocation. Plant J. 2009;57:798-809.

61. Lan P, Li W, Wen TN, Schmidt W. Quantitative phosphoproteome profiling of iron-deficient Arabidopsis roots. Plant Physiol. 2012;159:403-17.

62. Saenchai C, Bouain N, Kisko M, Prom-U-Thai C, Doumas P, Rouached $H$. The involvement of OsPHO1;1 in the regulation of iron transport through integration of phosphate and zinc deficiency signaling. Front Plant Sci. 2016;7:396.

63. Galkovskyi T, Mileyko Y, Bucksch A, Moore B, Symonova O, Price CA, et al. GiA Roots: software for the high throughput analysis of plant root system architecture. BMC Plant Biol. 2012:12:116.

64. Benke A, Stich B. An analysis of selection on candidate genes for regulation, mobilization, uptake, and transport of iron in maize. Genome. 2011;54:674-83.

\section{Submit your next manuscript to BioMed Central and we will help you at every step:}

- We accept pre-submission inquiries

- Our selector tool helps you to find the most relevant journal

- We provide round the clock customer support

- Convenient online submission

- Thorough peer review

- Inclusion in PubMed and all major indexing services

- Maximum visibility for your research

Submit your manuscript at www.biomedcentral.com/submit
) Biomed Central 